\title{
Perioperative Thromboelastometry for Adult Living Donor Liver Transplant Recipients with a Tendency to Hypercoagulability: A Prospective Observational Cohort Study
}

\author{
Yasmin Kamel $^{\mathrm{a}} \quad$ Ashraf Hassanin $^{\mathrm{a}} \quad$ Abdel Rahman Ahmed $^{\mathrm{b}}$ Emad Gad ${ }^{\mathrm{c}}$ Mohamed Afifi $^{\mathrm{b}}$ \\ Magdy Khalila Klaus Görlinger ${ }^{d, e}$ Khaled Yassen ${ }^{a}$
}

\footnotetext{
${ }^{a}$ Anesthesia Department of Liver Institute, Menoufia University, Sheeben El Kom, Egypt;

${ }^{b}$ Faculty of Medicine, Menoufia University, Sheeben El Kom, Egypt;

c Surgery Department of Liver Institute, Menoufia University, Sheeben El Kom, Egypt;

${ }^{\mathrm{d}}$ Department of Anaesthesiology and Intensive Care Medicine, University Hospital Essen, Germany;

e Tem International GmbH, Munich, Germany
}

\section{Keywords}

Adult living donor liver transplantation · Fibrinogen .

Hypercoagulability · Thromboelastometry $\cdot$ Thrombosis

\section{Summary}

Background: Hypercoagulability can lead to serious thromboembolic events. The aim of this study was to assess the perioperative coagulation status in liver transplant recipients with a tendency to hypercoagulability. Methods: In a prospective observational study (South African Cochrane Registry 201405000814129), 151 potential liver transplant recipients were screened for thrombophilic factors from October 2014 to June 2017, and 57 potential recipients fulfilled the inclusion criterion of presenting two or more of the following thrombophilic factors: low protein $\mathrm{C}$, low protein $\mathrm{S}$, low anti-thrombin, increased homocystein, increased antiphospholipid IgG/ IgM antibodies, increased lupus anticoagulant, and positive Factor $V$ Leiden mutation. Seven patients were excluded from the study because they fulfilled the exclusion criteria of cancelling the liver transplantation, oral anticoagulation, or intraoperative treatment with rFVIIa. Accordingly, 50 patients were included in the final analysis. Thromboelastometry (ROTEM) (EXTEM, INTEM and FIBTEM) and conventional coagulation tests (CCT) were performed preoperatively, during the anhepatic phase, post reperfusion, and on postoperative days (POD) 1, 3 and 7. ROTEM was used to guide blood product transfu- sion. Heparin was infused (60-180 U/kg/day) postoperatively for 3 days and then was replaced by low-molecular-weight heparin $(20 \mathrm{mg} / 12 \mathrm{~h})$. Results: FIBTEM MCF significantly increased postoperatively above reference range on POD 7 despite normal fibrinogen plasma concentrations $(p<0.05)$. Both EXTEM and INTEM demonstrated significant changes with the phases of transplantation $(p<0.05)$, but with no intra- or postoperative hypercoagulability observed. INTEM CT (reference range, 100-240 s) normalized on POD 3 and 7 (196.1 \pm 69.0 and $182.7 \pm 63.8 \mathrm{~s}$, respectively), despite prolonged aPTT $(59.7 \pm 18.7$ and $46.4 \pm 15.7 \mathrm{~s}$, respectively; reference range, 20-40 s). Hepatic artery thrombosis (HAT) and portal vein thrombosis (PVT) were reported in $12.0 \%$ and $2.0 \%$, respectively, mainly after critical care discharge and with high FIBTEM MCF values in 57\% on POD 3 and $86 \%$ on POD 7. Receiver operating characteristics curve analyses of FIBTEM MCF were significant predictors for thromboembolic events with optimum cut-off, area under the curve and standard error on POD $3(>23 \mathrm{~mm}$, 0.779 and $0.097 ; \mathrm{p}=0.004)$ and POD $7(>28 \mathrm{~mm}, 0.706$ and $0.089 ; p=0.020$ ). Red blood cells (mean $\pm S D, 8.68 \pm$ 5.81 units) were transfused in $76 \%$, fresh frozen plasma $(8.26 \pm 4.14$ units) in $62 \%$, and cryoprecipitate $(12.0 \pm$ 3.68 units) in $28 \%$ of recipients. None of the recipients received intraoperative platelet transfusion or any postoperative transfusion. Main transplant indication was hepatitis C infection in $82 \% .76 \%$ of recipients included

\section{KARGER}

(c) 2018 S. Karger GmbH, Freiburg

Fax +497614520714 
in this highly selected patient population showed increased lupus anticoagulant, $2 \%$ increased antiphospholipid IgG/lgM antibodies, 20\% increased homocysteine, $74 \%$ decreased anti-thrombin, 78\% decreased protein C, $34 \%$ decreased protein $\mathrm{S}$, and $24 \%$ a positive Factor $\mathrm{V}$ Leiden mutation. Overall 1-year survival was $62 \%$. Conclusion: A significant postoperative step-wise increase in FIBTEM MCF beyond the reference range was observed despite normal fibrinogen plasma concentrations, and FIBTEM MCF was a predictor for thromboembolic events in this study population, particularly after POD 3 and 7 on surgical wards when CCTs failed to detect this condition. However, the predictive value of FIBTEM MCF for postoperative HAT and PVT needs to be confirmed in a larger patient population. A ROTEM-guided anticoagulation regime needs to be developed and investigated in future studies.

(c) 2018 S. Karger GmbH, Freiburg

\section{Introduction}

Hypercoagulability can lead to serious vascular thromboembolic complications within the liver transplant graft vessels, which can result in a life-threatening situation. Krzanicki et al. [1] were able to demonstrate significant intraoperative thromboelastographic (TEG) evidence of hypercoagulability and reported that it is common (16-86\%) in liver transplantation. Conventional coagulation tests (CCT) have a limited ability to diagnose hypercoagulability. Recipients may be harmed if hypercoagulability is undiagnosed and inadequately treated, particularly in the immediate postoperative period. Recognized risk factors for thrombosis are generally related to one or more elements of Virchow's triad (stasis, vessel injury and hypercoagulability). Major surgery itself can induce a hypercoagulable state during the postoperative period, and this hypercoagulability has been implicated previously in the pathogenesis of postoperative thrombotic complications [2-4].

Hypercoagulability can readily be diagnosed by viscoelastic point of care (POC) coagulation analyzers such as thrombelastography (TEG) or rotational thromboelastometry (ROTEM). Hypercoagulability can be demonstrated in ROTEM analysis by shortened clotting time (CT) and increased (maximum) clot firmness $(\mathrm{MCF}>68 \mathrm{~mm})[2,5,6]$.

The aim of this study is to assess the perioperative coagulation process in living donor liver transplantation (LDLT) recipients with preoperative laboratory markers indicating a tendency to hypercoagulability by studying the intra- and postoperative coagulation using CCT and ROTEM, as well as the inter-relationship between them. In addition, we are reporting the incidence of postoperative thrombotic complications and the effects of prophylactic heparin infusion on CCT and ROTEM.

Perioperative Thromboelastometry for Adult

Living Donor Liver Transplant Recipients with a

Tendency to Hypercoagulability

\section{Patients and Methods}

This prospective observational study was approved by the local research and ethical committee (0082/2014) of the Liver Institute, Menoufia University, Egypt and registered at the South African Cochrane Registry (201405000814129).

151 potential liver transplant recipients were screened for thrombophilic factors from October 2014 to June 2017, and 57 potential recipients fulfilled the inclusion criterion of presenting two or more of the following thrombophilic factors: low protein $\mathrm{C}$, low protein $\mathrm{S}$, low anti-thrombin, increased homocystein, increased antiphospholipid IgG/IgM antibodies, increased lupus anticoagulant, and positive Factor V Leiden mutation. Protein $\mathrm{C}$ and $\mathrm{S}$ were determined with protein $\mathrm{C}$ and protein $\mathrm{S}$ reagent (Siemens Healthcare Diagnostics, Newark, DE, USA) on a Sysmex Automated Hematology Analyzer CA-1500 (Siemens Healthcare, Erlangen, Germany; reference range, 70-140\%; cut-off used in the study $<70 \%$ ). Anti-thrombin was measured with the Berichrom Anti-Thrombin III kit on a Sysmex Automated Hematology Analyzer CA-1500 (reference range, $79-112 \%$; cut-off used in the study $<79 \%$ ). Homocystein was determined by with the ADVIA Centaur Homocystein kit on a ADVIA Centaur Immunoassay Analyzer (Siemens Healthcare; reference range 5-12 $\mu \mathrm{mol} / \mathrm{l}$; cut-off used in this study $>12 \mu \mathrm{mol} / \mathrm{l}$ ). Antiphospholipid IgG/IgM antibodies (anticardiolipin, anti-phosphatidyl serine, anti-phosphatidyl inositol, anti-phosphatidic acid, and anti-beta-2-glycoprotein antigen) were detected with the Human Anti-Phospholipid Screening IgG/IgM ELISA kit (Alpha Diagnostics International, San Antonio, TX, USA) on a STAT FAX Multichannel Microplate Reader (Awareness Technology, Palm City, FL, USA; reference range $<10 \mathrm{U} / \mathrm{ml}$ for both IgG and IgM; cut-off used in this study > $10 \mathrm{U} / \mathrm{ml}$ ). Lupus anticoagulant was determined with Siemens LA1 screening reagent and LA2 confirmation reagent (Siemens Healthcare Diagnostics) on a Siemens BFII Coagulation Analyzer (Siemens Healthcare; reference range, normalized LA1/LA2 ratio, 0.8-1.2; cut-off used in this study, normalized LA1/LA2 ratio > 1.2). Factor $\mathrm{V}$ Leiden mutation was detected with the FV-PTH-MTHFR strip assay (ViennaLab Diagnostics, Vienna, Austria) on an AB 7500 Real Time PCR System (Applied Biosystems, Singapore; cut-off used in this study, positive (mutant)).

Exclusion criteria were cancellation of liver transplantation due to tumor progression or poor condition of the living donor liver, liver transplant recipients on oral anticoagulation, and any intra- or postoperative procoagulant therapy with activated recombinant factor VII (rFVIIa).

ROTEM $^{\circledR}$ delta assays (EXTEM, INTEM and FIBTEM; Tem International GmbH, Munich, Germany) and conventional coagulation tests (CCT) (prothrombin time (PT), activated partial thromboplastin time (aPTT), fibrinogen, platelet count, and international normalized ratio (INR)) were assessed preoperatively, during the anhepatic phase, post reperfusion, and on the 1st (POD 1), 3rd (POD 3) and 7th (POD 7) post-operative day. PT, aPTT, and fibrinogen were determined either by a Sysmex Automated Hematology Analyzer CA-1500 (operating according to the spectrophotometer principle) or a BFT II Analyzer (semi-automated analyzer operating according to the opto-mechanical measuring principle). Platelet count and hemoglobin concentration were measured by a Sysmex Automated Hematology Analyzer XT-1800i (Siemens Healthcare) or a Sysmex Automated Hematology Analyzer KX-21N (Siemens Healthcare).

INTEM and EXTEM represent the intrinsic and extrinsic coagulation pathway, respectively. Main ROTEM parameters are: clotting time (CT) in seconds (time from start of measurement until the first $2 \mathrm{~mm}$ of clot firmness are reached; reference range, INTEM CT 100-240 s, EXTEM CT 38-79 s), clot formation time (CFT) in seconds (time from 2 to $20 \mathrm{~mm}$ of clot firmness are reached; reference ranges INTEM CFT 30-110 s, EXTEM CFT 34-159 s), and maximum clot firmness (MCF) in mm. EXTEM and INTEM clot firmness is dependent on fibrinogen concentration, fibrin polymerization, factor XIII activity, platelet count, and platelet function (reference range $50-72 \mathrm{~mm}$ ). A10 is defined as the clot firmness $10 \mathrm{~min}$ after CT (reference ranges INTEM A10 44-66 mm, EXTEM A10 43-65 mm) and allows for an early estimation of MCF. FIBTEM MCF and A10 are reflecting clot firmness without platelet contribution and are therefore dependent on fibrinogen concentration, fibrin polymerization, and FXIII activity solely (reference ranges FIBTEM MCF 9-25 $\mathrm{mm}$, FIBTEM A10 7-23 mm). Reference ranges for all ROTEM parameters are presented in tables $2-4[7,8]$. 
Unfractionated heparin was infused (60-180 U/kg/day) postoperatively for 3 days and then replaced by low-molecular-weight heparin $(20 \mathrm{mg} / 12 \mathrm{~h})$.

General anesthesia was maintained with Desflurane (Baxter, Erlangen, Germany) in $\mathrm{O}_{2}$ /air mixture $\left(\mathrm{F}_{\mathrm{I}} \mathrm{O}_{2}=0.4\right)$, Fentanyl, and Rocuronium to keep the patient state index anesthesia depth monitoring between 25 and 50 (Sedline ${ }^{\circledR}$; Masimo, Irvine, CA, USA). An arterial line was placed in the non-dependent hand radial artery, and a central venous line was inserted ultrasound-guided in the right internal jugular vein.

Perioperative fluid regimens consisted of Ringer's acetate solutions (6-10 $\mathrm{ml} / \mathrm{kg} / \mathrm{h}$ ). Albumin 5\% was given to treat hypoalbuminemia related to ascites. Packed red blood cells (RBCs) were transfused to keep hematocrit above $25 \%$. ROTEM-guided intraoperative blood product transfusion was performed according to the protocol described by Görlinger [9] and Fayed et al. [10].

Transesophageal doppler (TED; Cardio QP, Deltex Medical, Chichester, UK) was placed into mid-esophagus. Boluses of colloids (gelatine or human albumin 5\%) were guided by an algorithm depending on TED, similar to the algorithm used by Sinclair et al. [11].

Liver transplantation was performed by the same surgeons ( 249 cases) without veno-venous bypass and temporary porto-caval shunt.

Deep venous thrombosis prophylaxis included elastic stockings and sequential compression system intermittent pneumatic compression (Tyco Healthcare, Kendall, MA, USA) for the lower limbs until early ambulation.

Body temperature was maintained using convective warming therapy (Bair Hugger ${ }^{\circledR}$ Temperature Management Unit, Model 750; Arizant Healthcare Inc., Eden Prairie, MN, USA) and warming of all infused fluids.

Postoperatively, patients were admitted to the intensive care unit directly from the operating room. Recipient complications, outcomes, blood transfusion requirements, perioperative fluid management as well as time of anesthesia and surgery were documented prospectively.

\section{Statistical Analysis}

We performed a prospective cohort study. In the present study blindness was only carried out for the main outcome assessor (level 3) (classification of blinding [12]: blinding for participants (level 1), health care providers (level 2), and main outcome assessor (level 3)). For sample size and power calculation, $a$ was set to 0.05 and maximum beta accepted was $20 \%$ with a minimum power of $80 \%$ in the present study. Sample size calculation was performed by using the IBM SPSS Sample Power Software (IBM, Armonk, NY, USA) and was confirmed by using the Lenth's Java Applets for Power and Sample Size and resulted in an overall sample size of 50 patients.

The IBM SPSS (Statistical Package for Social Science) program was used for data collection and analysis. Kolmogorov-Smirnov test was carried out and revealed no significance in the distribution of variables (normally distributed); this allowed for parametric statistics to be carried out.

Data were presented as percentage or as means and standard deviation (SD). Within group comparison was carried out using repeated measures ANOVA. The correction of $\mathrm{p}$ value for multiple testing was set to 0.01 to detect significance (Bonferroni correction of multiple comparisons) [13].

Receiver operating characteristics (ROC) curve analyses were used to assess the ability of ROTEM variables to discriminate postoperative thromboembolic events. Results were presented as area under the ROC curve (AUC) and standard error (SE). The overall test performance, assessed as the AUC, was graded based on the traditional academic point system (0.5-0.6: fail, 0.6-0.7: poor, 0.70-0.80: fair, 0.80-0.90: good, and 0.90-1.00: excellent) with concern of the p value (MedCalc, Version 13; MedCalc Software, Ostend, Belgium).

As secondary endpoints, cut-off values at the point estimate corresponding to the greatest Youden index (i.e., the largest difference between sensitivity and 1 - specificity over all points of the ROC curve) were calculated along with the respective sensitivities and specificities with their corresponding 95\% confidence intervals $(95 \% \mathrm{CI})$. These cut-off values are frequently considered a potential 'optimum' cut-off, although the optimum biological cut-off may differ. 95\% CIs were computed based on the observed proportion using Clopper and Pearson's method [14]. Furthermore, positive and negative predictive values for these respective optimum cut-off values were calculated not considering uncertainty in the selection of the cut-off.

\section{Results}

The study was conducted at the Anesthesia Department, Liver Institute, Menoufia University, Egypt from October 2014 to June 2017. The Liver Institute is a hospital specialized on liver disease and a reference center for advanced liver disease and surgery in Egypt. 57 out of 151 (37.8\%) potential recipients for liver transplantation screened preoperatively fulfilled the inclusion criterion of presenting two or more thrombophilic factors. Seven patients were excluded from the study because they fulfilled at least one exclusion criterion. Accordingly, 50 out of 151 (33.1\%) patients were included in the final analysis.

Recipient characteristics: Mean age and weight were $45.62 \pm 9.08$ years and $79.88 \pm 12.66 \mathrm{~kg}$, respectively. The mean operation time was $12.45 \pm 3.35 \mathrm{~h}$.

Male/female ratio was $47 / 3$ ( $94 \%$ male). The most common relationship between donors and recipients was the son (20\%). Main indications for transplantation were combined hepatitis $\mathrm{C}$ virus (HCV) and hepatocellular carcinoma (HCC) 18/50 (36\%). HCV without HCC accounted for 23/50 (46\%).

RBCs (mean \pm SD $8.68 \pm 5.81$ units) were transfused in $38 / 50$ (76\%), fresh frozen plasma (8.26 \pm 4.14 units) in 31/50 (62\%), and cryoprecipitate $(12.0 \pm 3.68$ units) in $14 / 50(28 \%)$ of recipients. None of the recipients received intraoperative platelet transfusion or any postoperative transfusion. 12/50 (24\%) patients went through the liver transplantation without any blood transfusion.

All recipients received crystalloids in the form of Ringer's acetate $(10.38 \pm 3.17 \mathrm{l})$, colloids $(2.84 \pm 1.34 \mathrm{l})$ and human albumin $5 \%$ (11.62 \pm 4.15 units) ( 1 unit human albumin contains $50 \mathrm{ml}$ ).

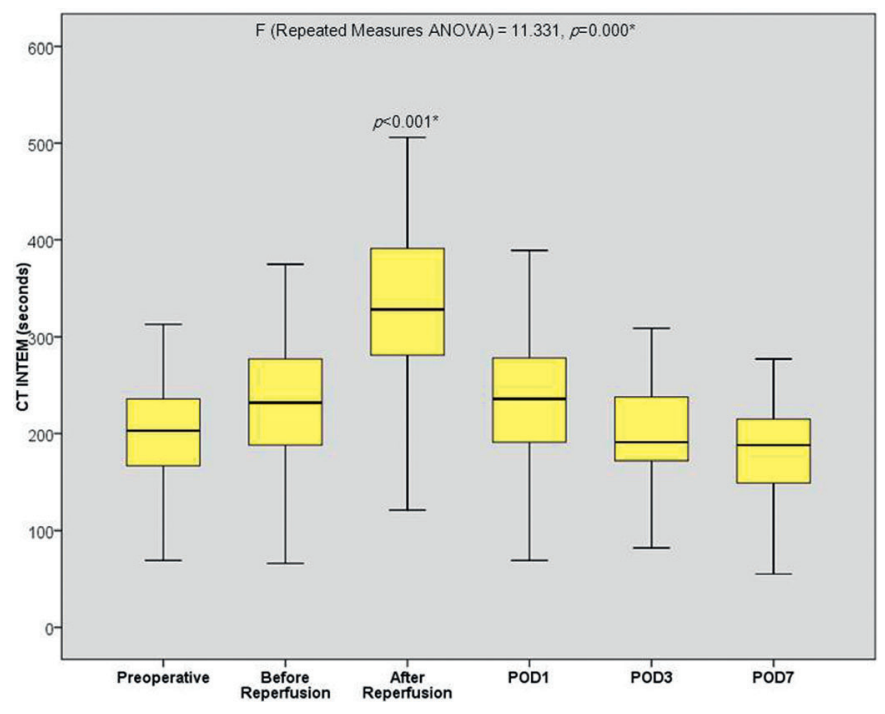

Fig. 1. Box-Whisker plots for perioperative changes in INTEM CT (reference range 100-240 s) for the 50 liver transplant recipients. Results are expressed as maximum, minimum, median (line within the box) with 25th-75th percentiles (error bars) at selected time points. Repeated measures ANOVA was used, INTEM CT changes were significant all over the measuring point, ${ }^{*} \mathrm{p} \leq 0.001$. $\mathrm{P}$ values above each box indicate its significance when compared to the preoperative value using a pair-wise comparison with Bonferroni adjustment for multiple comparisons ( $\mathrm{p}<0.01$ is considered as significant). $\mathrm{POD}=$ postoperative day. 
Table 1. Perioperative changes in conventional coagulation tests $(\mathrm{CCT})^{\mathrm{a}}$

\begin{tabular}{|c|c|c|c|c|c|c|c|c|}
\hline $\begin{array}{l}\text { Conventional } \\
\text { parameter(RR) }\end{array}$ & Preoperative & Before reperfusion & After reperfusion & POD1 & POD3 & POD7 & $\begin{array}{l}\text { Repeated } \\
\text { measure } \\
\text { ANOVA (F) }\end{array}$ & $\mathrm{p}$ value \\
\hline $\begin{array}{l}\mathrm{Hb} \\
\qquad(13-17 \mathrm{~g} / \mathrm{dl})\end{array}$ & $11.0 \pm 1.9$ & $9.1 \pm 1.4^{*}$ & $9.3 \pm 1.3^{*}$ & $9.1 \pm 1.4^{*}$ & $8.6 \pm 0.9^{*}$ & $9.6 \pm 1.1^{*}$ & 24.010 & $0.000^{* *}$ \\
\hline $\begin{array}{l}\text { Platelet count } \\
\qquad\left(150-450 \times 10^{9} / 1\right)\end{array}$ & $71.5 \pm 58.5$ & $61.5 \pm 34.8$ & $57.8 \pm 30.8$ & $40.6 \pm 22.3^{*}$ & $33.6 \pm 20.9^{*}$ & $51.0 \pm 36.9$ & 13.609 & $0.000^{* *}$ \\
\hline $\begin{array}{l}\text { INR } \\
\qquad(<1.3)\end{array}$ & $1.6 \pm 0.4$ & $1.7 \pm 0.5$ & $2.1 \pm 0.5^{\star}$ & $2.2 \pm 0.6^{*}$ & $1.8 \pm 0.6$ & $1.4 \pm 0.4$ & 22.810 & $0.000^{* *}$ \\
\hline $\begin{array}{l}\text { aPTT } \\
\quad(20-40)\end{array}$ & $50.3 \pm 14.2$ & $60.5 \pm 20.0$ & $75.9 \pm 21.4^{*}$ & $74.5 \pm 22.6^{*}$ & $59.7 \pm 18.7^{\star}$ & $46.4 \pm 15.7$ & 25.645 & $0.000^{* *}$ \\
\hline $\begin{array}{l}\text { Fibrinogen } \\
\qquad(200-400 \mathrm{mg} / \mathrm{l})\end{array}$ & $134 \pm 61$ & $111 \pm 69$ & $77 \pm 31^{*}$ & $97 \pm 43^{*}$ & $174 \pm 67^{*}$ & $173 \pm 100$ & 45.000 & $0.000^{* *}$ \\
\hline
\end{tabular}

$\mathrm{POD}=$ Postoperative day, $\mathrm{HB}=$ hemoglobin concentration, $\mathrm{INR}=$ international normalized ratio, aPTT = activated partial thromboplastin time, $\mathrm{RR}=$ reference range.

a Units and reference ranges presented for each variable. $\mathrm{P}<0.01$ is considered as significant.

*Significant pair-wise comparison to preoperative values with Bonferroni adjustment for multiple comparisons $(\mathrm{p}<0.01)$, ${ }^{* *}$ Significant with repeated measure $\operatorname{ANOVA}(\mathrm{p}<0.01)$.

Table 2. Perioperative changes in INTEM results ${ }^{\mathrm{a}}$

\begin{tabular}{|c|c|c|c|c|c|c|c|c|}
\hline $\begin{array}{l}\text { INTEM } \\
\text { parameter (RR) }\end{array}$ & Preoperative & $\begin{array}{l}\text { Before } \\
\text { reperfusion }\end{array}$ & $\begin{array}{l}\text { After } \\
\text { reperfusion }\end{array}$ & POD1 & POD3 & POD7 & $\begin{array}{l}\text { Repeated } \\
\text { measure } \\
\text { ANOVA (F) }\end{array}$ & $\mathrm{p}$ value \\
\hline $\begin{array}{l}\text { CT } \\
\qquad(100-240 s)\end{array}$ & $203.1 \pm 79.6$ & $237.7 \pm 76.6$ & $310.4 \pm 133.7^{*}$ & $250.9 \pm 152.4$ & $196.1 \pm 69.0$ & $182.7 \pm 63.8$ & 11.331 & $0.000^{* *}$ \\
\hline $\begin{array}{l}\text { CFT } \\
\qquad(30-100 s)\end{array}$ & $295.4 \pm 175.0$ & $308.8 \pm 136.1$ & $372.6 \pm 192.6$ & $301.3 \pm 151.4$ & $309.2 \pm 172.5$ & $203.3 \pm 101.0^{*}$ & 6.658 & $0.000^{* *}$ \\
\hline $\begin{array}{l}\text { Alpha } \\
\qquad\left(70-83^{\circ}\right)\end{array}$ & $56.0 \pm 13.0$ & $54.5 \pm 11.2$ & $54.4 \pm 15.5$ & $60.3 \pm 14.4$ & $60.0 \pm 12.5$ & $67.7 \pm 11.3^{*}$ & 9.187 & $0.000^{* *}$ \\
\hline $\begin{array}{l}\text { A10 } \\
\qquad(44-66 \mathrm{~mm})\end{array}$ & $33.8 \pm 6.3$ & $31.6 \pm 4.5$ & $29.9 \pm 7.5$ & $34.1 \pm 5.3$ & $32.7 \pm 3.6$ & $38.6 \pm 7.6^{*}$ & 13.748 & $0.000^{* *}$ \\
\hline $\begin{array}{l}\text { MCF } \\
\qquad(50-72 \mathrm{~mm})\end{array}$ & $44.2 \pm 11.6$ & $47.4 \pm 11.1$ & $45.3 \pm 13.7$ & $48.7 \pm 18.8$ & $47.3 \pm 12.2$ & $55.7 \pm 12.9^{*}$ & 5.016 & $0.000^{* *}$ \\
\hline
\end{tabular}

Preoperative coagulation screening for the 50 recipients finally included in this study showed an increased lupus anticoagulant, antiphospholipid IgG/IgM antibodies and homocystein in 76\%, 2\% and $20 \%$, respectively, a decreased anti-thrombin, protein $\mathrm{C}$ and protein S in 74\%, 78\% and 34\%, respectively, and Factor V Leiden mutation in $24 \%$. This corresponds to an incidence of $25.2 \%, 0.7 \%$, $6.6 \%, 24.5 \%, 25.8 \%, 11.3 \%$, and $7.9 \%$ in the overall patient population of potential liver transplant recipients $(n=151)$ screened for this study.

Complications recorded were bile leak in 22/50 (44\%) followed by sepsis in $10 / 50$ patients (20\%). Hepatic artery thrombosis (HAT) and portal vein thrombosis (PVT) were reported in 6/50 (12\%) and $1 / 50(2 \%)$ patients, respectively, mainly after critical care discharge and with high FIBTEM MCF values, in $57 \%$ on
POD 3, $86 \%$ on POD 7. Here, $1 / 6$ patients with thrombosis presented a combined HAT and PVT. The overall 1-year survival in this group of recipients with hypercoagulability was $62 \%$.

There were significant changes in conventional coagulation test results (INR, aPTT, and fibrinogen plasma concentration) post reperfusion compared to preoperative values as analyzed by pairwise comparison with Bonferroni adjustment for multiple comparisons ( $\mathrm{p}<0.01$ ) (table 1). Furthermore, ROTEM analysis showed significant changes in CT, CFT, alpha angle, A10, and MCF in INTEM and EXTEM during the study period when tested with a repeated measures ANOVA $(\mathrm{p}<0.01)$, but with no intra- or postoperative hypercoagulability observed. INTEM CT (reference range 100-240 s) normalized on POD 3 and 7 (196.1 \pm 69.0 and $182.7 \pm 63.8$ s, respectively), despite prolonged aPTT $(59.7 \pm 18.7$ 
Table 3. Perioperative changes in EXTEM results ${ }^{\mathrm{a}}$

\begin{tabular}{|c|c|c|c|c|c|c|c|c|}
\hline $\begin{array}{l}\text { EXTEM } \\
\text { parameter (RR) }\end{array}$ & Preoperative & $\begin{array}{l}\text { Before } \\
\text { reperfusion }\end{array}$ & $\begin{array}{l}\text { After } \\
\text { reperfusion }\end{array}$ & POD1 & POD3 & POD7 & $\begin{array}{l}\text { Repeated } \\
\text { measure } \\
\text { ANOVA (F) }\end{array}$ & $\mathrm{p}$ value \\
\hline $\begin{array}{l}\text { CT } \\
\qquad(38-79 \mathrm{~s})\end{array}$ & $106.9 \pm 61.8$ & $121.2 \pm 84.0$ & $128.6 \pm 79.7$ & $150.6 \pm 158.2$ & $86.6 \pm 48.9$ & $80.4 \pm 39.8$ & 4.877 & $0.005^{* *}$ \\
\hline $\begin{array}{l}\text { CFT } \\
\qquad(34-159 \text { s) }\end{array}$ & $364.4 \pm 192.9$ & $417.9 \pm 229.6$ & $348.7 \pm 178.8$ & $389.5 \pm 165.4$ & $375.3 \pm 214.8$ & $264.5 \pm 165.7$ & 4.470 & $0.001^{* *}$ \\
\hline $\begin{array}{l}\text { Alpha } \\
\qquad\left(63-83^{\circ}\right)\end{array}$ & $55.0 \pm 14.0$ & $48.2 \pm 14.7$ & $57.1 \pm 16.5$ & $50.4 \pm 13.6$ & $58.7 \pm 16.8$ & $63.4 \pm 17.8$ & 7.426 & $0.000^{* *}$ \\
\hline $\begin{array}{l}\text { MCF } \\
\quad(50-72 \mathrm{~mm})\end{array}$ & $33.0 \pm 8.6$ & $32.2 \pm 5.6$ & $39.6 \pm 7.0^{*}$ & $37.1 \pm 6.5$ & $40.8 \pm 5.1^{\star}$ & $42.4 \pm 6.8^{\star}$ & 20.657 & $0.000^{* *}$ \\
\hline $\begin{array}{l}\text { A10 } \\
\quad(43-65 \mathrm{~mm})\end{array}$ & $45.8 \pm 12.5$ & $41.6 \pm 13.5$ & $47.4 \pm 14.1$ & $41.6 \pm 10.5$ & $50.4 \pm 13.5$ & $53.5 \pm 14.0$ & 7.426 & $0.001^{* *}$ \\
\hline $\begin{array}{l}\mathrm{POD}=\text { Postoper } \\
\text { mum clot firmne } \\
{ }^{\text {ap }}<0.01 \text { is consi } \\
{ }^{*} \text { Significant pair- } \\
{ }^{*} \text { Significant rep }\end{array}$ & $\begin{array}{l}\text { ay, CT = clotti } \\
=\text { reference ra } \\
\text { as significant, } \\
\text { omparison to } \\
\text { measure ANO }\end{array}$ & $\begin{array}{l}\text { me, CFT = clo } \\
\text { perative values } \\
p<0.01) .\end{array}$ & Bonferroni a & ment for mul & $\begin{array}{l}0=\text { amplitude } \\
\text { comparisons ( }\end{array}$ & $\begin{array}{l}\text { ot firmness } 10 \\
.01) \text {. }\end{array}$ & after CT, $N$ & maxi- \\
\hline
\end{tabular}

Table 4. Perioperative changes in FIBTEM MCF

\begin{tabular}{|c|c|c|c|c|c|c|c|c|}
\hline $\begin{array}{l}\text { FIBTEM } \\
\text { parameter (RR) }\end{array}$ & Preoperative & $\begin{array}{l}\text { Before } \\
\text { reperfusion }\end{array}$ & $\begin{array}{l}\text { After } \\
\text { reperfusion }\end{array}$ & POD1 & POD3 & POD7 & $\begin{array}{l}\text { Repeated } \\
\text { measure } \\
\text { ANOVA (F) }\end{array}$ & $\mathrm{p}$ value \\
\hline $\begin{array}{l}\text { MCF } \\
\qquad(8-24 \mathrm{~mm})\end{array}$ & $11.1 \pm 6.1$ & $13.1 \pm 5.4$ & $12.9 \pm 4.1$ & $16.3 \pm 4.4^{\star}$ & $21.8 \pm 7.2^{\star}$ & $26.7 \pm 8.7^{*}$ & 66.635 & $0.000^{* *}$ \\
\hline
\end{tabular}

Table 5. Receiver operating characteristics (ROC) curve analysis for FIBTEM MCF ${ }^{\mathrm{a}}$

\begin{tabular}{|c|c|c|c|c|c|c|}
\hline $\begin{array}{l}\text { ROTEM } \\
\text { variable }\end{array}$ & $\begin{array}{l}\text { AUC (SE), } \\
(95 \% \text { CI) p value }\end{array}$ & $\begin{array}{l}\text { 'Optimum' } \\
\text { cut-off }\end{array}$ & $\begin{array}{l}\text { Sensitivity, \% } \\
(95 \% \text { CI })\end{array}$ & $\begin{array}{l}\text { Specificity, \% } \\
(95 \% \text { CI })\end{array}$ & $\begin{array}{l}\text { Positive predictive } \\
\text { value }\end{array}$ & $\begin{array}{l}\text { Negative predictive } \\
\text { value }\end{array}$ \\
\hline $\begin{array}{l}\text { FIBTEM MCF } \\
\text { preoperative }\end{array}$ & $\begin{array}{l}0.582(0.156) \\
p=0.790\end{array}$ & & & & & \\
\hline $\begin{array}{l}\text { FIBTEM MCF } \\
\text { before reperfusion }\end{array}$ & $\begin{array}{l}0.663(0.146) \\
p=0.264\end{array}$ & & & & & \\
\hline $\begin{array}{l}\text { FIBTEM MCF } \\
\text { after reperfusion }\end{array}$ & $\begin{array}{l}0.580(0.143) \\
p=0.576\end{array}$ & & & & & \\
\hline $\begin{array}{l}\text { FIBTEM MCF } \\
\text { POD1 }\end{array}$ & $\begin{array}{l}0.654(0.136) \\
p=0.256\end{array}$ & & & & & \\
\hline $\begin{array}{l}\text { FIBTEM MCF } \\
\text { POD3 }\end{array}$ & $\begin{array}{l}0.779(0.097) \\
\mathrm{p}=0.004^{*}\end{array}$ & $>23$ & $\begin{array}{l}71.43 \\
(29.0-96.3)\end{array}$ & $\begin{array}{l}74.42 \\
(58.8-86.5)\end{array}$ & 31.2 & 94.1 \\
\hline $\begin{array}{l}\text { FIBTEM MCF } \\
\text { POD7 }\end{array}$ & $\begin{array}{l}0.706(0.088) \\
\mathrm{p}=0.020^{*}\end{array}$ & $>28$ & $\begin{array}{l}85.71 \\
(42.1-99.6)\end{array}$ & $\begin{array}{l}62.79 \\
(46.7-77.0)\end{array}$ & 27.3 & 96.4 \\
\hline
\end{tabular}

${ }^{a} \mathrm{AUC}$ (SE) and 'optimum' cut-off (Youden index) to discriminate thromboembolic events with the corresponding sensitivity (95\% confidence interval (95\% CI)), specificity, positive and negative predictive values derived from the data if ROC AUC was considered as significant $\left({ }^{*} \mathrm{p}<0.05\right)$.

and $46.4 \pm 15.7 \mathrm{~s}$, respectively; reference range, $20-40 \mathrm{~s})$. The INTEM and EXTEM results are displayed in figure 1 and tables 2 and 3 .

A significant step-wise increase in FIBTEM MCF was observed from POD 1 to POD 3 and POD 7 with $16.3 \pm 4.4,21.8 \pm 8.7$ and
$26.7 \pm 8.7 \mathrm{~mm}$ (reference range $8-24 \mathrm{~mm}$ ). All postoperative values were significantly higher than the preoperative ones (fig. 2, table 4).

No significant correlations were found between most of the conventional coagulation tests (CCT) and ROTEM parameters ( $p>0.05)$, except for the post-reperfusion fibrinogen plasma con- 


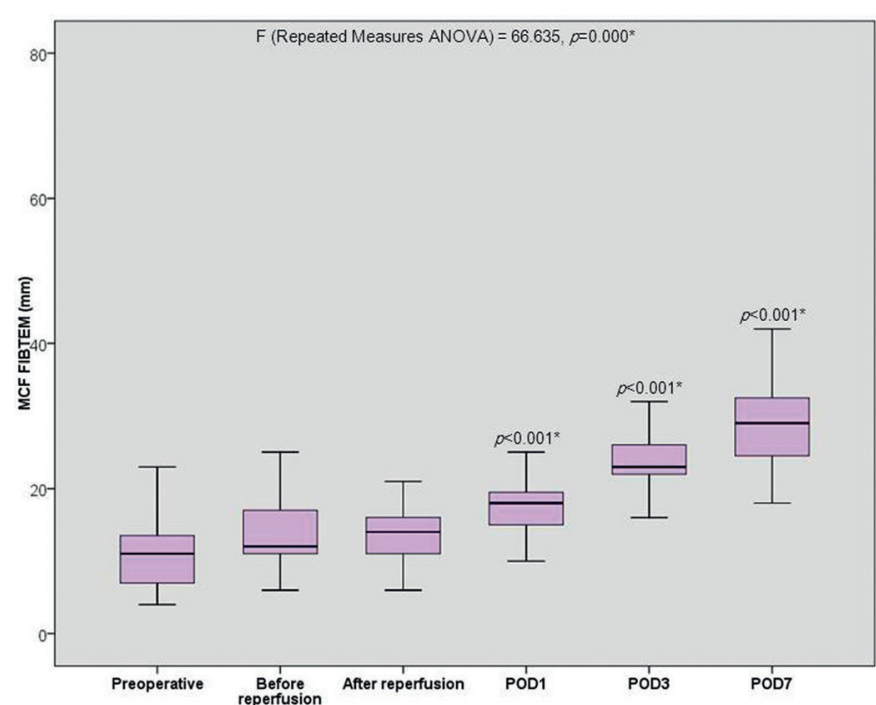

Fig. 2. Box-Whisker plots for perioperative changes in FIBTEM MCF (reference range $9-25 \mathrm{~mm}$ ) for the 50 liver transplant recipients. Results are expressed as maximum, minimum, median (line within the box) and 25th and 75th percentiles (error bars) at selected time points. Repeated measures ANOVA was used, FIBTEM MCF changes were significant all over the measuring point, ${ }^{*} p<0.001$. $\mathrm{P}$ values above each box indicate its significance when compared to the preoperative value using a pair-wise comparison with Bonferroni adjustment for multiple comparisons ( $\mathrm{p}<0.01$ is considered statistically significant). POD = Postoperative day.

centration and the post-reperfusion FIBTEM MCF, but there was no significant correlation between platelet count and INTEM and EXTEM MCF.

Analyzing ROTEM variables from the pooled data set demonstrated that only FIBTEM MCF was able to predict an increase in coagulation activity in the enrolled patient population with preoperative precursors of hypercoagulability. This was demonstrated by the step-wise increase in FIBTEM MCF from POD 1 to POD 3 and POD 7, with a maximum effect on POD 7.

ROC curve analyses of FIBTEM MCF were significant predictors for thromboembolic events with optimum cut-off value, AUC and SE on POD 3 (>23 mm, 0.779 (0.097); p = 0.004) and POD 7 (>28 $\mathrm{mm}, 0.706(0.089) ; \mathrm{p}=0.020)$, as displayed in figure 3 and table 5 .

\section{Discussion}

This study helped to shed light on several important points regarding the hemostatic balance in patients during and after liver transplantation. First of all, there was a significant and step-wise increase in FIBTEM MCF from POD 1 to 7 , indicating an increase in fibrin polymerization, despite normal plasma fibrinogen concentrations. This increase can predispose to thrombosis within the vascular anastomoses of the liver graft. Six out of 50 (12\%) recipients suffered from HAT and/or PVT, mainly after discharge from the critical care unit and during their stay on the surgical ward. One out of 50 (2\%) recipients developed both HAT and PVT. Thrombotic events in the liver graft are an important issue which

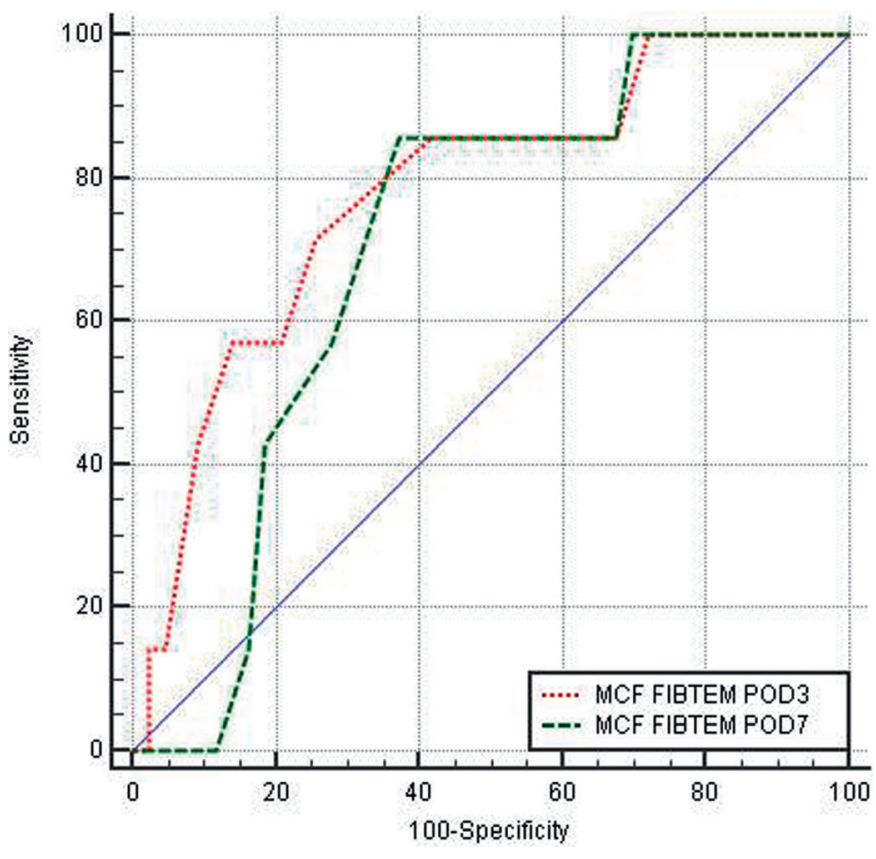

Fig. 3. Receiver operating characteristics (ROC) curve analysis for preoperative and postoperative FIBTEM MCF to predict thromboembolic complications (hepatic artery thrombosis and/or portal vein thrombosis) after liver transplantation. A FIBTEM MCF cut off value of $23 \mathrm{~mm}$ at POD 3 (ROC area under the curve (AUC) 0.779; p < 0.05) and of $28 \mathrm{~mm}$ at POD 7 (ROC AUC 0.706, p < 0.05 ) can be used to predict thromboembolic events in the liver graft in this study population. $\mathrm{MCF}=$ maximum clot firmness; $\mathrm{POD}=$ postoperative day.

can result in graft failure and patient death, and this highlights the importance of extending ROTEM monitoring in patients at risk for thrombosis as included in this study. The ROC analysis performed in this study as well as in the study published by Hincker et al. [2] have clearly demonstrated that ROTEM can provide a better risk assessment for thrombosis compared to CCT.

Rossetto et al. [15] evaluated the thromboelastometry profile of cirrhotic and non-cirrhotic patients with non-neoplastic PVT and healthy volunteers. Similar to our results, they found no significant differences in standard coagulation tests as well as in INTEM and EXTEM results between PVT patients, both with and without cirrhosis, and healthy control. However, they demonstrated also a significantly higher FIBTEM MCF in non-cirrhotic patients with PVT compared to healthy volunteers ( 19 vs. $11 \mathrm{~mm}$; p < 0.05). Accordingly, they suggested that the FIBTEM MCF can be a useful tool to discriminate non-cirrhotic patients with PVT from those without thrombotic events. This is in line with the results of our study, where ROC analysis at POD 3 and POD 7 with a FIBTEM MCF cut-off value of $>23 \mathrm{~mm}$ and $>28 \mathrm{~mm}$ could predict thromboembolic events in the liver graft with a sensitivity of $71.4 \%$ and $85.7 \%$, a specificity of $74.4 \%$ and $62.8 \%$, a positive predictive value of $31.2 \%$ and $27.3 \%$, and a negative predictive value of $94.1 \%$ and $96.4 \%$.

Zanetto et al. [16] reported that a FIBTEM MCF $>25 \mathrm{~mm}$ in patients with (HCC was associated with a 5-fold increased PVT risk even in Child A patients. Here, cox multivariate analysis confirmed HCC and increased FIBTEM MCF to be independently associated with increased PVT risk. 
In this context, the development of an alternative and/or prolonged antithrombotic therapy guided by thromboelastometry may have the potential to reduce thromboembolic events and subsequent graft failure in this vulnerable patient population. The idea of using viscoelastic testing to monitor hemostasis in liver disease may have the advantage that these tests assess hemostasis in whole blood and therefore provide more global information on pro- and anticoagulants as well as on cellular components (platelets and leukocytes) involved in this process [16-20].

Another important observation in our study was that $57 / 151$ $(37.8 \%)$ of the patients screened for this study were found to have at least two risk factors for hypercoagulability and thrombosis such as low protein $\mathrm{C}$, low protein $\mathrm{S}$, low anti-thrombin, increased homocystein, increased antiphospholipid IgG/IgM antibodies, increased lupus anticoagulant, or positive Factor V Leiden mutation. Related to the patient population screened for this study (151 potential liver recipients), this corresponds to an incidence of $0.7 \%$ antiphospholipid antibodies, $6.6 \%$ for increased homocysteine, 7.9\% for Factor V Leiden mutation, 11.3\% for decreased protein S, $25.8 \%$ for decreased protein C, $24.5 \%$ for decreased anti-thrombin, and $25.2 \%$ for increased lupus anticoagulant. This high incidence of risk factors for thrombosis - in particular the high incidence of positive lupus anticoagulant testing - is an important finding and should lead to further studies in cooperation with other centers in Egypt and overseas to investigate whether this is a local problem or represents a general issue in patients on a liver transplant waiting list [21-26]. This would provide important information for developing a protocol for perioperative hemostasis management for recipients in this part of the world, which might be different from other protocols used in overseas centers. However, the observed incidence of $25.2 \%$ for increased lupus anticoagulant in our study is in line with the increased incidence of lupus anticoagulant between 18 and $61 \%$ reported by other authors [27-31] for patients with hepatitis C, cirrhosis, and carcinoma. Notably, the main transplant indication in our patient population was HCV infection in $82 \%(41 / 50)$, even combined with HCC in $43 \%$ (18/41). Furthermore, the inclusion criteria for this study were two or more pre-existing thrombophilic factors detected in the preoperative coagulation screening. This highly selected patient population explains the high incidence of thrombophilic factors reported in the 50 patients finally included in this study (e.g., 76\% lupus anticoagulant in the study group $(\mathrm{n}=50)$ compared to $25.2 \%$ in the patient population screened $(n=151)$ and listed for liver transplantation at Menoufia University). We are aware that oral anticoagulants - vitamin $\mathrm{K}$ antagonists as well as direct oral anticoagulants (DOACs) - and heparin can interfere with lupus anticoagulant assays $[32,33]$. This was one reason to exclude liver transplant recipients with oral anticoagulation from the study. However, anti-factor Xa tests have not been performed in our preoperative screening. This might be considered as a limitation of our study.

The lack of correlation between CCT and ROTEM parameters found in our study is in line with findings in other studies. Inconsistent correlation between FIBTEM MCF and plasma fibrinogen concentration in patients undergoing liver transplantation can be explained by the presence of dysfibrinogenemia in this patient population which is associated with fibrin polymerization disorders [34-40]. Furthermore, it has been demonstrated in several publications and in a meta-analysis by Segal et al. [41] that prolonged conventional coagulation tests are not associated with bleeding in cirrhosis. In contrast, hemostasis management guided by viscoelastic testing has been shown to reduce transfusion requirements in patients with cirrhosis $[19,20]$. DePietri et al. [42], Schofield et al. [43], and Mallet et al. [44] demonstrated a disagreement between conventional coagulation testing and viscoelastic testing regarding hypo- and hypercoagulability in patients undergoing major liver resection. Herbstreit et al. [45] is in -line with our finding that CT in thromboelastometry shows poor correlation with both PT and aPTT in patients with cirrhosis. The absence of important cellular structures of the hemostatic system, such as platelets, leukocytes and endothelial cells, in CCT can explain the lack of correlation between these tests and viscoelastic assays performed with whole blood. During surgery and invasive interventions, many patients with cirrhosis and increased INR do not bleed and do not need any transfusion of blood products [19, $20,46,47]$. Accordingly, 26\% (12/50) and 38\% (19/50) of the patients did not require any $\mathrm{RBC}$ and plasma transfusion during surgery, and no transfusions were necessary after liver transplantation in our study.

Another important question is whether or not the coagulation changes that developed in the postoperative period as the step-wise increase in FIBTEM MCF is specific for this patient population of hypercoagulable recipients. On the one hand, the increase in fibrinogen after surgery and trauma is a common and well-known phenomenon but, on the other hand, FIBTEM MCF did not predict thrombosis in non-cirrhotic patients undergoing non-cardiac surgery $[2,48]$.

It is still not yet clear when hypercoagulability in this patient population will return to the preoperative baseline coagulation values, but the present data suggest that hypercoagulability after major abdominal surgery can persist beyond the known duration of surgical stress response after similar procedures $[49,50]$. Prediction of this hypercoagulability, particularly in the postoperative period, and implementing measures to help reduce the incidence of thromboembolic events would help to improve outcome.

Since 1997, Handa et al. [51] and Traverso et al. [52] observed a relationship between hypercoagulable TEG and prothrombotic screening tests. Supporting our study results, it has recently been demonstrated that TEG and ROTEM can distinguish between groups of patients with hypercoagulability and patients who have experienced a venous thromboembolic event $[2,15,16]$.

Finally the survival rate in this study is clearly affected by the incidence of vascular complications which is higher than in other overseas centers. Here, we have to improve our knowledge on contributing factors such as biliary leak and sepsis which can be conducive in developing HAT. However, this study has been performed in a challenging group due to their hypercoagulability tendency and also due to the procedure of LDLT. Compared to cadav-
410

Transfus Med Hemother 2018;45:404-412 DOI: $10.1159 / 000489605$
Kamel/Hassanin/Ahmed/Gad/Afifi/Khalil/ Görlinger/Yassen 
eric liver transplantation, LDLT is an important surgical issue since it is technically more challenging anastomosing smaller graft vessels in LDLT than in cadaveric whole liver transplant.

Ayala et al. [53] added that HAT is generally believed to result primarily from surgical techniques, but also other non-surgical reasons, such as rejection, weak flow in the hepatic artery, the presence of Factor V Leiden in the graft and the recipient, as well as changes in the hemostatic functions can contribute [54-61]. Accordingly, our surgical team came to the same conclusion and reported that vascular and biliary complications were associated with a reduction in survival and that the prevention and proper treatment of these complications is required to achieve better survival among patients undergoing LDLT [62].

In conclusion, this study demonstrated that a continuous postoperative increase in FIBTEM MCF despite normal or delayed increase in fibrinogen plasma concentration was associated with an increased incidence of HAT and PVT in LDLT. Future studies should assess whether an extension of ROTEM monitoring beyond 1 week after surgery on the surgical ward and an alternative, postoperative, anticoagulation regime guided by ROTEM is superior to the actual standard of care of thromboprophylaxis with low-molecular-weight heparin, in particular in high-risk patients with known hypercoagulability.

\section{Acknowledgements}

The authors would like to thank the patients participating in this study and Dr. Amr Yassen, Anesthesia Professor from Mansoura University, Egypt for his help in revising the manuscript.

\section{Disclosure Statement}

KG works as the medical director of Tem International since July 2012.

\section{References}

1 Krzanicki D, Sugavanam A, Mallett S: Intraoperative hypercoagulability during liver transplantation as demonstrated by thromboelastography. Liver Transpl 2013;19:852-861.

- 2 Hincker A, Feit J, Sladen RN, Wagener G: Rotational thromboelastometry predicts thromboembolic complications after major non-cardiac surgery. Crit Care 2014; 18:549.

3 Cayley WE: Preventing deep vein thrombosis in hospital patients. BMJ 2007;335:147-151.

4 Schreiber MA, Differding J, Thorborg P, Mayberry JC Mullins RJ: Hypercoagulability is most prevalent early after injury and in female patients. J Trauma 2005;58 475-480

5 McCrath DJ, Cerboni E, Frumento RJ, Hirsh AL, Bennett-Guerrero E: Thromboelastography maximum amplitude predicts postoperative thrombotic complications including myocardial infarction. Anesth Analg 2005; 100:1576-1583.

-6 Dimitrova-Karamfilova A, Patokova Y, Solarova T, Petrova I, Natchev G: Rotational thromboelastography for assessment of hypercoagulation and thrombosis in patients with cardiovascular disease. J Life Sci 2012; 6 $28-35$

7 Tem Innovations: Reference Ranges ROTEM delta. Reference Ranges 2015-08 Ver0008.doc; Edition 2015-08.

8 Gouvêa G, Diaz R, Auler L, Toledo R, Soluri A, Haack AG, de Oliveira MM, Vilanova B, Machado VR, Martinho JM: Perioperative coagulation profile in living liver donors as assessed by rotational thromboelastometry. Liver Transpl 2010;16:387-392.

9 Görlinger K: Coagulation management during liver transplantation. Hämostaseologie 2006;26(3 suppl 1):S64-S76.

10 Fayed NA, Abdallah AR, Khalil MK, Marwan IK: Therapeutic rather than prophylactic platelet transfusion policy for severe thrombocytopenia during liver transplantation. Platelets 2014;25:576-586.

11 Sinclair S, James S, Singer M: Intraoperative intravascular volume optimization and length of hospital stay after repair of proximal femoral fracture: randomized controlled trial. BMJ 1997;315:909-912.

12 Boutron I, Guittet L, Estellat C, Moher D, Ravaud P: Reporting methods of blinding in randomized trials assessing nonpharmacological treatments. PLoS Med 2007;4:e61.
Bland JM, Altman DG: Multiple significance tests: the Bonferroni method. BMJ 1995;310:170.

14 Clopper C, Pearson ES: The use of confidence or fiducial limits illustrated in the case of the binomial. Biometrika 1934;26:404-413.

15 Rossetto V, Spiezia L, Senzolo M, Rodriguez-Castro KI, Maggiolo S, Simioni P: Whole blood rotation thromboelastometry $\left(\right.$ ROTEM $\left.^{\circledR}\right)$ profiles in subjects with non-neoplastic portal vein thrombosis. Thromb Res 2013;132:e131-134.

16 Zanetto A, Senzolo M, Vitale A, Cillo U, Radu C, Sartorello F, Spiezia L, Campello E, Rodriguez-Castro K, Ferrarese A, Farinati F, Burra P, Simioni P: Thromboelastometry hypercoagulable profiles and portal vein thrombosis in cirrhotic patients with hepatocellular carcinoma. Dig Liver Dis 2017;49:440-445.

17 Anil H, Kiliç Yildirim G, Harmanci K, Bozkurt Turhan A, Akay OM, Bör Ö, Aydoğdu S, Kocak A: Thromboelastogram as a tool to predict hypercoagulability in children with cystic fibrosis. Clin Appl Thromb Hemost 2018;24:348-352.

18 Hartmann M, Szalai C, Saner FH. Hemostasis in liver transplantation: Pathophysiology, monitoring, and treatment. World J Gastroenterol 2016;22:1541-1550.

19 Bedreli S, Sowa JP, Gerken G, Saner FH, Canbay A: Management of acute-on-chronic liver failure: rotational thromboelastometry may reduce substitution of coagulation factors in liver cirrhosis. Gut 2016;65: 357-358.

20 Debernardi Venon W, Ponzo P, Sacco M, Mengozzi G, Raso S, Valpreda A, Rizzetto M, Marzano A: Usefulness of thromboelastometry in predicting the risk of bleeding in cirrhotics who undergo invasive procedures. Eur J Gastroenterol Hepatol 2015;27:13131319.

21 Tripodi A, D’Ambrosio R, Padovan L, Tosetti G, Aghemo A, Primignani M, Chantarangkul V, Peyvandi F, Colombo M: Evaluation of coagulation during treatment with directly acting antivirals in patients with hepatitis C virus related cirrhosis. Liver Int 2017;37: 1295-1303.

22 Kamei H, Nakamura T, Nagai S, Ishigami M, Hamajima N: Possible association between the methylenetet rahydrofolate reductase gene C677T polymorphism and preexisting portal vein thrombosis in liver transplant recipients. Exp Clin Transplant 2016;14:313-316.
23 Qi X, Li H, Liu X, Yao H, Han G, Hu F, Shao L, Guo X: Novel insights into the development of portal vein thrombosis in cirrhosis patients. Expert Rev Gastroenterol Hepatol 2015;9:1421-1432.

24 Fan J, Nishida S, Selvaggi G, Levi D, Tekin A, Weppler $\mathrm{D}$, Tzakis AG: Factor V Leiden mutation is a risk factor for hepatic artery thrombosis in liver transplantation. Transplant Proc 2013;45:1990-1993.

25 Furmańczyk-Zawiska A, Tronina O, Baczkowska T, Chmura A, Durlik M: The significance of antiphospholipid antibodies in liver recipients. Transplant Proc 2013;45:1983-1989.

26 Pereboom IT, Adelmeijer J, van der Steege G, van den Berg AP, Lisman T, Porte RJ: Prothrombotic gene polymorphisms: possible contributors to hepatic artery thrombosis after orthotopic liver transplantation. Transplantation 2011;92:587-593.

27 Abdel-Wahab N, Talathi S, Lopez-Olivo MA, SuarezAlmazor ME: Risk of developing antiphospholipid antibodies following viral infection: a systematic review and meta-analysis. Lupus 2018;27:572-583

28 Vassalo J, Spector N, de Meis E, Rabello LS, Rosolem MM, do Brasil PE, Salluh JI, Soares M: Antiphospholipid antibodies in critically ill patients with cancer: a prospective cohort study. J Crit Care 2014;29:533-538.

29 Oksüzoglu G, Bayraktar Y, Arslan S, Celik I, Arslan M, Sivri B, Kirazli S, Kayhan B: Portal vein thrombosis in cirrhotics: related with anticardiolipin antibodies? Hepatogastroenterology 2003;50:1527-1530.

30 Quintarelli C, Ferro D, Valesini G, Basili S, Tassone G, Violi F: Prevalence of lupus anticoagulant in patients with cirrhosis: relationship with beta-2-glycoprotein I plasma levels. J Hepatol 1994;21:1086-1091.

31 Park CJ, Cho HI, Kim SI: A study on changes of coagulation inhibitors and fibrinolysis inhibitors in patients with liver cirrhosis and hepatoma. J Korean Med Sci 1991;6:1-6.

32 Seheult JN, Meyer MP, Bontempo FA, Chibisov I. The effects of indirect- and direct-acting anticoagulants on lupus anticoagulant assays: a large, retrospective study at a coagulation reference laboratory. Am J Clin Pathol 2017;147:632-640.

33 Hoxha A, Banzato A, Ruffatti A, Pengo V: Detection of lupus anticoagulant in the era of direct oral anticoagulants. Autoimmun Rev 2017;16:173-178. 
-34 Vucelic D, Jesic R, Jovicic S, Zivotic M, Grubor N, Trajkovic G, Canic I, Elezovic I, Antovic A: Comparison of standard fibrinogen measurement methods with fibrin clot firmness assessed by thromboelastometry in patients with cirrhosis. Thromb Res 2015;135:11241130.

35 Seo H, Choi JH, Moon YJ, Jeong SM: FIBTEM of thromboelastometry does not accurately represent fibrinogen concentration in patients with severe hypofibrinogenemia during liver transplantation. Ann Transplant 2015;20:342-350.

- 36 Jeong SM, Song JG, Seo H, Choi JH, Jang DM, Hwang GS: Quantification of both platelet count and fibrinogen concentration using maximal clot firmness of thromboelastometry during liver transplantation. Transplant Proc 2015;47:1890-1895.

37 Song JG, Jeong SM, Jun IG, Lee HM, Hwang GS: Fiveminute parameter of thromboelastometry is sufficient to detect thrombocytopenia and hypofibrinogenaemia in patients undergoing liver transplantation. $\mathrm{Br} \mathrm{J}$ Anaesth 2014;112:290-297.

38 Yang Lu S, Tanaka KA, Abuelkasem E, Planinsic RM, Sakai T: Clinical applicability of rapid thrombelastography and functional fibrinogen thrombelastography to adult liver transplantation. Liver Transpl 2014;20: 1097-1105.

-39 Tripodi A, Primignani M, Chantarangkul V, Viscardi Y, Dell'Era A, Fabris FM, Mannucci PM: The coagulopathy of cirrhosis assessed by thromboelastometry and its correlation with conventional coagulation parameters. Thromb Res 2009;124:132-136.

40 Francis JL, Armstrong DJ: Fibrinogen-bound sialic acid levels in the dysfibrinogenaemia of liver disease. Haemostasis 1982;11:215-222.

41 Segal JB, Dzik WH: Paucity of studies to support that abnormal coagulation test results predict bleeding in the setting of invasive procedures: an evidence-based review. Transfusion 2005;45:1413-1425.

42 DePietri L, Montalti R, Begliomini B, Reggiani A, Lancellotti L, Giovannini S, Di Benedetto F, Guerrini G, Serra V, Rompianesi G, Pasetto A, Gerunda GE: Thromboelastographic changes in liver and pancreatic cancer surgery: hypercoagulability, hypocoagulability or normocoagulability? Eur J Anaesthesiol 2010;27: 608-616.
43 Schofield N, Sugavanam A, Henley M, Thompson K, Riddell A, Mallett SV: An in vitro study comparing two dose regimes of fresh frozen plasma on conventional and thromboelastographic tests of coagulation after major hepatic resection. Transfus Med 2015;25: 85-91.

44 Mallett SV, Sugavanam A, Krzanicki DA, Patel S, Broomhead RH, Davidson BR, Riddell A, Gatt A, Chowdary P: Alterations in coagulation following major liver resection. Anaesthesia 2016;71:657-668.

45 Herbstreit F, Winter EM, Peters J, Hartmann M: Monitoring of haemostasis in liver transplantation: comparison of laboratory based and point of care tests. Anaesthesia 2010;65:44-49.

46 Saner FH, Kirchner C. Monitoring and treatment of coagulation disorders in end-stage liver disease. Visc Med 2016;32:241-248.

47 Kirchner C, Dirkmann D, Treckmann JW, Paul A, Hartmann M, Saner FH, Görlinger K: Coagulation management with factor concentrates in liver transplantation: a single-center experience. Transfusion 2014;54:2760-2768.

48 Oelsner WK, Engstrom SM, Benvenuti MA, An TJ, Jacobson RA, Polkowski GG, Schoenecker JG: Characterizing the acute phase response in healthy patients following total joint arthroplasty: predictable and consistent. J Arthroplasty 2017;32:309-314.

49 Weinberg L, Scurrah N, Parker FC, Dauer R, Marshall J, McCall P, Story D, Smith C, McNicol L: Markers of coagulation activation after hepatic resection for cancer: evidence of sustained upregulation of coagulation. Anaesth Intensive Care 2011;39:847-853.

50 Van Haren RM, Valle EJ, Thorson CM, Guarch GA, Jouria JM, Andrews DM, Sleeman D, Levi JU, Livingstone AS, Proctor KG: Long-term coagulation changes after resection of thoracoabdominal malignancies. J Am Coll Surg 2014;218:846-854.

51 Handa A, Cox D, Pasi K, Perry D, Hamilton G: Thrombelastography: an effective screening test for prothrombotic states. Thromb Haemost 1997;78:440.

52 Traverso C, Arcelus J, Gomez E, Luna D., Lopez-Cantareno M, Garcia J: Prospective assessment of the risk of deep vein thrombosis in elective abdominal surgery. Predictive role of thromboelastography. Thromb Haemorrh Disord 1993;71:9-15.
53 Ayala R, Martínez-López J, Cedena T, Bustelos R, Jimenez C, Moreno E, Ribera C: Recipient and donor thrombophilia and the risk of portal venous thrombosis and hepatic artery thrombosis in liver recipients. BMC Gastroenterol 2011;11:130.

54 Wozney P, Zajko AB, Bron KM, Point S, Starzl TE: Vascular complications after liver transplantation: a 5-year experience. AJR Am J Roentgenol 1986;147: 657-663.

55 Dodd GD 3rd, Memel DS, Zajko AB, Baron RL, Santaguida LA: Hepatic artery stenosis and thrombosis in transplant recipients: Doppler diagnosis with resistive index and systolic acceleration time. Radiology 1994; 192:657-661.

56 Abbasoglu O, Levy MF, Testa G, Obiekwe S, Brkic BS, Jennings LW, Goldstein RM, Husberg BS, Gonwa TA, Klintmalm GB: Does intraoperative hepatic artery flow predict arterial complications after liver transplantation? Transplantation 1998;66:598-601.

57 Hirshfield G, Collier JD, Brown K, Taylor C, Frick T, Baglin TP, Alexander GJ: Donor factor V Leiden mutation and vascular thrombosis following liver transplantation. Liver Transpl Surg 1998;4:58-61.

58 Dunn TB, Linden MA, Vercellotti GM, Gruessner RW: Factor V Leiden and hepatic artery thrombosis after liver transplantation. Clin Transplant 2006;20:132135.

59 Stahl RL, Duncan A, Hooks MA, Henderson JM, Millikan WJ, Warren WD: A hypercoagulable state follows orthotopic liver transplantation. Hepatology 1990;12:553-558.

60 Bispo M, Marcelino P, Freire A, Martins A, Mourão L, Barroso E: High incidence of thrombotic complications early after liver transplantation for familial amyloidotic polyneuropathy. Transpl Int 2009;22:165-171.

61 Lisman T, Porte RJ: Hepatic artery thrombosis after liver transplantation: more than just a surgical complication? Transpl Int 2009;22:162-164.

62 Gad EH, Alsebaey A, Lotfy M, Eltabbakh M, Sherif AA: Complications and mortality after adult to adult living donor liver transplantation: a retrospective cohort study. Ann Med Surg (Lond) 2015;4:162-171. 